\title{
THE UNEXPECTED COURSE OF INSTITUTIONAL INNOVATION PROCESSES: INQUIRY INTO INNOVATION PROCESSES IN LAND DEVELOPMENT PRACTICES ACROSS EUROPE
}

\author{
W. TIMMERMANS ${ }^{1}$, T. VAN DIJK ${ }^{2}$, P. VAN DER JAGT ${ }^{1}$, F. ONEGA-LOPEZ ${ }^{3} \&$ R. CRECENTE ${ }^{3}$ \\ ${ }^{1}$ Wageningen University and Research Center. \\ ${ }^{2}$ University of Groningen. \\ ${ }^{3}$ Universidade de Santiago de Compostela.
}

\begin{abstract}
Changes in planning practices can be explained from the prevailing theoretical juxtaposition of 'institutional design' and 'institutional evolution'; two schools of thought that are at the extremes of assumptions on modifiability. The two extremes are considered to be inextricably linked to each other and cannot be separated; institutional design at a higher level highly influences institutional evolution at a lower level. In this paper we add the opposite direction of their interdependence. We found that small and sometimes even unexpected efforts of institutional design at a low level of scale can, when aggregated, result into an evolution of collective institutions at a higher level. We participated in a cooperative project between research and practice, which was established as an exchange project on innovation in land development. We investigated the genesis of institutional change in land development, which is a specific regional planning instrument. We analyzed 40 planning practices that were presented by land agencies from seven EU regions (Flanders, the Netherlands, North Rhine-Westphalia, Galicia, Portugal, Hungary, and Lithuania) as their most innovative ones. We studied the histories of 14 of them intensively, using grounded data gathered in visits, discussions, and in-depth interviews with key persons. We found great similarity across these 14 cases in terms of the distinctive patterns relating to local processes leading up to systemic innovations: seemingly small, local, often unexpected and unpredictable occurrences appeared to have set the process of innovation in motion. The evidence demonstrates the relevance of the landscape metaphor found in theories on Complex Adaptive Systems for understanding institutional change in planning practice.
\end{abstract}

Keywords: complexity theory, innovation, land development, planning.

\section{INTRODUCTION}

How do shifts in planning practice happen? Do practices change as a result of intentional and deliberate action undertaken to establish such changes, or are changes the product of the merging of autonomous processes and efforts at micro-level that amplify into more systemic change? We inquired into these questions using as our empirical basis a cooperative project involving research and practice, the EU INTERREG project named FARLAND, which was an exchange project on innovative approaches in land development. The FARLAND project was established to enable the participating land development agencies to learn from each other's innovative practices, from an implicit institutional design perspective.

We tested the assumption that planning approaches would allow intentional modification, and investigated the genesis of institutional change in the land development practices in the participating regions. We analyzed about 40 innovative practices that were presented by land development agencies from seven EU regions (Flanders, the Netherlands, North Rhine-Westphalia [NRW], Galicia, Portugal, Hungary and Lithuania) as their most innovative ones. We analyzed 14 of them intensively (Table 1), using grounded data gathered in visits, discussions, and in-depth interviews with key persons [1]. 
Table 1: List of 14 innovative land development projects examined.

\begin{tabular}{|c|c|c|c|}
\hline & Country & Name & Innovation \\
\hline 1 & Hungary & $\begin{array}{l}\text { Integrated Water and Land } \\
\text { Management, Jánd -Bereg } \\
\text { Pilot Project }\end{array}$ & $\begin{array}{l}\text { Sustainable land management by combining } \\
\text { institutional development, organizational } \\
\text { development, planning of participation, nature } \\
\text { conservation, and village development }\end{array}$ \\
\hline 2 & Hungary & Curriculum development & $\begin{array}{l}\text { Incorporating integrated land development in } \\
\text { higher education }\end{array}$ \\
\hline 3 & Lithuania & $\begin{array}{l}\text { Land consolidation project } \\
\text { in Telsiai County }\end{array}$ & $\begin{array}{l}\text { A new phase of land management in Lithuania } \\
\text { is land consolidation }\end{array}$ \\
\hline 4 & Lithuania & Zemaitija National Park & Functional zoning plan in large natural areas \\
\hline 5 & Galicia & BanTeGal & Land-banking principle based on user rights \\
\hline 6 & Galicia & Vila Verde Project & $\begin{array}{l}\text { Communal farming activities against land } \\
\text { fragmentation }\end{array}$ \\
\hline 7 & Portugal & Baixo Vouga Lagunar & $\begin{array}{l}\text { Flexible land consolidation in harmony with } \\
\text { nature }\end{array}$ \\
\hline 8 & Portugal & $\begin{array}{l}\text { Land Consolidation Project } \\
\text { of the Luz Parish }\end{array}$ & $\begin{array}{l}\text { Land consolidation as a compensation for big } \\
\text { infrastructural interventions }\end{array}$ \\
\hline 9 & Netherlands & 'Schetsschuit' Ruiten Aa & $\begin{array}{l}\text { Instrument to connect different stakeholder } \\
\text { perceptions through visualization }\end{array}$ \\
\hline 10 & Netherlands & $\begin{array}{l}\text { Public Private Partnership, } \\
\text { Meerstad }\end{array}$ & $\begin{array}{l}\text { Public private partnership for sustainable green } \\
\text { spaces in urban rural areas. }\end{array}$ \\
\hline 11 & Belgium & Demand-driven approach & $\begin{array}{l}\text { A new internal procedure for the initiation } \\
\text { of projects: every green space stakeholder } \\
\text { (governmental body, private organization) } \\
\text { encountering a spatial 'problem' whose } \\
\text { solution goes beyond their own capacities can } \\
\text { file a request for intervention with the } \\
\text { Flemish Land Agency }\end{array}$ \\
\hline 12 & Belgium & Merode project & $\begin{array}{l}\text { Integrated rural development using different } \\
\text { time tracks (e.g. quick wins) }\end{array}$ \\
\hline 13 & $\begin{array}{l}\text { North Rhine- } \\
\text { Westphalia }\end{array}$ & $\begin{array}{l}\text { ILEK (Integrated rural } \\
\text { development strategy), } \\
\text { Bocholter Aa }\end{array}$ & $\begin{array}{l}\text { Integrated rural development strategy to point } \\
\text { out the strengths and weaknesses of a region } \\
\text { and to analyze the opportunities for economic } \\
\text { improvement. }\end{array}$ \\
\hline 14 & $\begin{array}{l}\text { North Rhine- } \\
\text { Westphalia }\end{array}$ & Milchenbach & $\begin{array}{l}\text { Integrated Land Consolidation procedure } \\
\text { including village renewal }\end{array}$ \\
\hline
\end{tabular}

We scrutinized the hypothesis underlying the FARLAND project that agencies could copy each other's innovations to deal with their own problems. This not only reflects the instrumentalist paradigm of government, which presupposes planned and targeted predictable interventions, but also reflects the presumption of evolution [2], which treats planning as constantly improving instead of constantly changing. During the project, therefore, our research took the alternative perspective that sought to 
understand the processes producing the innovations. We studied the stories behind a set of innovations, and discovered that they obeyed basic principles from the Complexity Theory founded by Prigogine and Stengers [3], who was a great inspiration to Enzo Tiezzi in his book The essence of time (2003).

In this paper we present our findings, which argue for a grass-roots perspective on innovation, clarified with some concepts from complexity theory that allow a better understanding of the coincidental, interrelated, and micro-level processes encountered in the reality of planning innovation. We first discuss key concepts of institutional change and complexity, and then the state of the art of land development in the six countries. We present our methodology based on Grounded Theory and appropriate strands from Complexity Theory, and analyze in detail one specific example of innovative practice in land development. The concluding section presents a morphology of the innovation process, and discusses the consequences for a better understanding of institutional change using Complexity Theory. We also point out where current theories and visualizations fail to cover the processes we observed in reality.

\section{PERSPECTIVES ON INSTITUTIONAL CHANGE}

The issue of institutional change, which has clear bearings on spatial planning, is increasingly treated as an object of planning research. By institutions, we mean all the entities that try to establish stability in human interaction. Agreements on ways in which we interact make life in society more predictable, and individual spheres of operation less uncertain. But these agreements are constantly changing. Planning works within a given institutional context, but also creates and adapts laws, flows of money, organizations, processes of participation, etc. Institutional change is both a given in planning and a product of planning.

Buitelaar [4] reviewed the prevailing theoretical juxtaposition of 'institutional design' and 'institutional evolution'; two schools of thought that are at the extremes of the continuum of assumptions on modifiability. The design paradigm stresses the deliberate creation of any institution (even basic human rights) by people in response to an apparent need for society to agree on the issue. It paints an instrumental and rational picture of the way institutions are created and adapted. By contrast, the evolution paradigm states that societies (and in particular market-based democracies) will constantly produce new variations in institutions, and select from this variety on the basis of efficiency, to create stability in interaction (a school of thought originating from Hayek [5]. Today, theories of policy change, much inspired by the work of Kingdon [6], tend to favor the latter perspective. These two extremes cannot be separated in practice because they include each other; or as Buitelaar [4] put it: the technical rationality of a collective agent to enhance a piece of legislation will have to engage in an iterative process of socially embedding the ideas on improvement. In other words: evolution at a lower level of scale is an inevitable part of the design at a higher level of scale. This still emphasizes the central role of governments in concerting institutional change, however, although we found evidence downplaying this central role.

In the FARLAND project, we had the opportunity to inquire deeply into the stories behind a set of systemic 'innovations', as institutional changes were called in the project. It is hard to tell when 'change' can be legitimately defined as 'innovation', as most of the literature on innovation is related to the manufacturing industry, generating a wide-ranging literature where the words innovation and technology are rarely more than one line apart (the journal name Technovation even merges the two words). Most of the literature deals with physical products, although innovation in services in developed countries is increasingly addressed in conjunction with technical innovations, being either the driving force $[7,8]$, the analogy $[9,10]$, or complementary $[11,12,13]$. The concept of innovation seems to be absent from the literature pertaining to policy making and planning, so the use of 'institutional change' is more appropriate here. 
What is interesting for our study on institutional change is the notion of the early S-curve in the life cycle, used especially in the literature relating innovation processes to complexity theory [14, $15,16,17,18]$. Ayres [18] described the process of innovation as nonlinear, distinguishing five phases. Technological change starts with a 'breakthrough', as a new product is developed. After that it may be rapidly improved and production is scaled up. After a period of maturation, the limitations of the product become more and more obvious and a new breakthrough can be expected. Kash and Rycroft [15] also described breakthroughs and noted the difference between radical or dramatic changes and smaller ones focusing on amelioration.

The idea of maturation curves applying to newly designed products or services provides what the theories on institutional change lack: a perspective departing from the micro-level and looking at the path toward the system level. We therefore want to add to the mutual inclusion of evolution and design argued by Buitelaar [4] the opposite direction of their interdependence: evolution of collective institutions can be the aggregated effect of a multitude of smaller efforts of institutional design at a low level of scale. In other words: systemic innovation can be the aggregated effect of microevolution. Although individuals cannot change national laws, the cumulative effect of variations introduced by individuals - in response to local problems - can result in changes to the larger system, as they become more frequent and manage to resonate with aligning trends.

Whether or not a case of micro-innovation actually enters the breakthrough stage depends on the chain reaction of resonance and momentum in its wider systemic environment; this is where complexity theory comes in, as it emphasizes the nonlinear, unpredictable trajectories of change in complex systems. We studied several processes of institutional change by considering innovative practices in land development and by analyzing them from the point of view of Complexity Theory. Before we explain our use of this theoretical perspective in Section 4, we first discuss the state of the art of land development in Europe, and more specifically in the seven regions of the project that we had good access to.

\section{STATE OF THE ART OF LAND DEVELOPMENT}

We define land development as 'a policy program or public task intended to adapt the nature and location of land use and/or land ownership for the sake of public or private objectives' [19]. Land development implements regional and rural development measures at a specific site under the spatial planning scheme [20]. It can affect various land use types, such as farmland, wildlife areas, landscape elements, small villages, and infrastructure works. Land development practices in the countries we investigated differ, depending on social, economic, and physical circumstances, societal challenges, and institutions. As a consequence, actual practices can be extremely diverse, despite the shared definition of land development. This effect is further increased as the organizations go through different innovation processes. In the complex systems of policy implementation so typical of the planning debate, there are many layers of analysis. Here we briefly address diversity in the layer of the primary object of the system (i.e. rural areas and the challenges they face), how this object fits into a broader multifunctional policy setting (i.e. managing non-agricultural objectives), and how it is organizing or reorganizing its organizational form.

Social, economic, and physical circumstances have consequences for the practices used in land development $[21,22,23]$. Population densities differ greatly between the countries, with population densities in the Netherlands, Flanders, and NRW of over 400 inhabitants per $\mathrm{km}^{2}$, compared to densities of about 100 in Portugal and Hungary, and well below 100 in Lithuania and Galicia. In the latter four countries, most of the population is concentrated in the urban areas. As a consequence, the perception of 'rural' and 'urban' is different in the seven countries: in the Netherlands, Flanders, and NRW, areas with population densities below 600 per $\mathrm{km}^{2}$ are considered rural. Rural land use is also 
highly different between these countries. North Rhine-Westphalia and Galicia have relatively large afforested areas, while Portugal and Hungary have large Natura 2000 areas. Average farm size is relatively large in the three North-West European countries compared to the others. In Lithuania and Hungary, privatization of state land and the restoration of private property have led to a dual situation, with big cooperatives on the one hand and many small private parcels on the other, resulting in severe land fragmentation. Similar degrees of land fragmentation are found in Galicia and Portugal, although there the cause is land abandonment.

Societal differences have caused countries to develop specific specializations in terms of land development. In the highly urbanized regions of the Netherlands, Flanders, and NRW, integrated approaches have been developed, integrating agriculture, nature, recreation, tourism, forestry, village renewal, and other land use types [24, 25, 26]. Within this context, Flanders has further developed the system of land development for nature, while NRW has developed methods and instruments to prevent disadvantages to farming due to extensive public infrastructure. In the Netherlands, approaches involving public-private cooperation were developed, as well as a system of land banking that is innovative in the Europe context [27]. Portugal, Lithuania, and Galicia have specialized in addressing extreme fragmentation. Hungary does not have a legislative basis for land consolidation and specializes in influencing land use through economic incentives.

The organizational implementation of land development also differs between the participating countries. In Lithuania and the Netherlands, land development has been decentralized and has been made the responsibility of regional governments (counties and provinces, respectively) supported by national land development agencies. In Flanders and NRW, it is specialized rather than sector-oriented regional agencies that are responsible for land development. In Portugal and Galicia, specialized services have been established within the departments of agriculture and forestry, which means that their tasks are more sector-specific. In all countries, land development is regarded as a public task, although private companies play an important role in the implementation process. In the Netherlands, Flanders, and NRW, participation by various partners has led to co-financing schemes, while the owners also share part of the costs, which is not the case in Portugal, Lithuania, or Galicia. An associated problem in Galicia and Lithuania is the lack of a proper land administration system.

The first quick-scan study performed in our project found correlations between the life-cycle phase of a national land development system and the aspects having the highest level of 'innovation' [1]. When we asked all participants to name the five innovations they were most proud of, the newly established land development agencies appeared to be most actively engaged in innovating their procedures. Growing and mature agencies were innovative in terms of the organizational, procedural, and measures levels, while the relatively long-established agencies were still introducing innovations at the procedural level. At the same time, we found that the innovations indicated by newly established agencies were highly influenced by EU and national driving forces. The growing and mature agencies appeared to innovate in response to national, regional, and local drivers, while the older established agencies did so mainly through regional and local drivers. Overall, EU drivers tended to produce innovation in terms of procedures, while national drivers produced changes in measures and procedures, regional drivers in procedures, measures, and organizations, and finally local drivers in procedures and organizations.

The large differences found as regards the state of the art of land development in the seven participating regions show how limited an instrumental perspective on cross-national learning is; despite the fact that professionals in all seven regions all speak of land development, the contexts are so completely different that communication is highly imperfect. This is why we argue that exchange of practical information is only meaningful when the stories behind innovations are understood; we should find out how systemic innovations emerge. We have added to cross-regional learning in the 
project by using the innovative approaches to analyze and understand the process of innovation in the different regions, using concepts from Complexity Theory.

\section{STRANDS OF COMPLEXITY THEORY}

We claim that thinking in terms of complexity theory is vital for an understanding of institutional change in planning practices. An instrumental perspective or design paradigm is hardly realistic, and as we argued in Section 1, any idea departing from a centralist player needs critical inquiry. Since these systems of policy implementation through planning practices have their own dynamics involving competing and communicating subsystems, institutional change is much more likely to be an emergent property, resulting from unpredictable trajectories of micro-innovation. When we say that institutional change is an emergent property, we do not mean that it is beyond any logic, control, or understanding. We mean that adopting the perspective offered by complexity theory can lead to a better understanding.

Scientists like Prigogine [28, 29] studying nonlinear dynamic systems and Kauffman [30] studying self-organization can be considered as founding fathers of Complexity Theory, which now has been used by many authors to understand complex features in a broad range of natural and human systems [31, 32, 33]. In complex systems, causal processes 'cannot be accessed by simple analysis' [34]. Cilliers [35] claims that although we can increase our knowledge of a particular system, 'this knowledge is limited and we have to acknowledge these limits'. We consider the world to be composed of systems made up by large numbers of parts with many interactions, and small changes in parameters can drastically change the behavior of the system as a whole - the outcomes and forms of complex systems can be surprising and unpredictable.

Initial research was oriented on so-called closed systems. In the 70s, computers became more powerful resulting in research on computer simulations and artificial life, as referred to by Gleick and Lewin [31, 33], also computer simulations on social systems occurred [36]. Soon the study of historic civilizations was connected to complexity theory as referred to by Waldrop and Lewin [32, 33]. Recently research started to focus on open systems. The science of networks developed [37] including the concept of complex adaptive systems (CAS). Complexity Theory is now recognized and used by scientists in many different disciplines, such as ecosystems [38], leadership [39], organizations [40] and also area development [41, 42]. Complexity science developed from studying closed systems to the study of open systems, including real life. Prigogine [43] introduces the arrow of time in open systems stating that mankind offers creativity leading to unpredictable and irreversible features in human complex systems. Here Prigogine inspires Tiezzi and his students $[44,45,46]$ to establish their research in urban systems often referring to the world of arts always with a strong focus on overcoming the 'opposition between interest in nature on one side, in man on the other', as Prigogine called it in his foreword to The essence of time. In early complexity theory literature, complex adaptive systems were related to natural and biophysical systems that learn to evolve and adapt to their changing environment.

As stated, complexity theory has been widely adopted by the social, cultural, and economic sciences [31, 32, 33, 37, 38]. Artigani [39] discusses leadership, demonstrating how military leaders in history, operating on the basis of limited knowledge, were more successful when they were better prepared to adapt to unforeseen occurrences. Other authors discussed the role of project management in making firms adaptive to discontinuous work flows and turbulent environments [47, 48]; did numerous interviews to distinguish what factors make a company able to overcome a sudden extreme disruption in its environment, in their case the September 11 attacks [49]; and discussed organizational vitality and leadership aspects in relation to complexity [40, 51, 52]. In the social sciences, most notably in the literature on organization, the early theories were supplemented because the cognitive capabilities (reason, deliberation, expectation, strategic action) needed to be accounted for in social interaction. Anderson [52] provided an elaborate overview of this evolution in theories and 
the resulting types, which diverge from the cybernetic approach (deterministic dynamic systems) in that they center on interaction between individuals. The strands of theory concentrating on interaction are very relevant to planning and institutional change and Anderson [52] refers to these strands as Complex Adaptive Systems (CASs). CASs are about the behavior of agents rather than parameters. Concepts from the CAS approach are particularly relevant to the subject of this paper, as it specifically includes the notion of order being an emergent property of individual interactions at a lower level of aggregation [52, 53]. Instead of a central controller, co-evolution by agents and subsystems leads to increased pay-off or fitness. Within CAS theory, Andersen distinguishes three ways of modeling: cellular automata (cells with a geographical location responding to parameters in neighboring cells), neural networks (of interrelated nodes regardless of location), and genetic algorithms; all, however, struggle to combine realism and simplicity.

Despite these developments in complexity thinking in social systems as organizations, thinking about complexity is relatively new in planning and regional development literature. This can be explained by the fact that planning is deeply rooted in the concept of control. However, following Pirsig [54], we can distinguish physical, natural, and human systems interacting everywhere at the same time. Physical and chemical processes are everywhere on earth and, for example, the moon; biological processes can be considered as life; social processes as complex life; intellectual processes are considered as specific for mankind. From physical to intellectual processes, complexity is rising; so planning and regional development can be considered as dealing with highly complex systems. Literature is available describing complex characteristics of complex systems in planning and regional development $[41,42,55]$ discussing nonlinear changes leading to unexpected results in urban planning. Also literature describes complex phenomena as wicked planning [56] and swarm planning [57], all stressing the uncertainty features in the outcome of a planning process. So far literature aiming at a better understanding of complex (and uncertainty) features in planning has focused on simulating and modeling the object of planning $[58,59]$ and on theoretical studies $[60$, 61, 62]. In this paper, we add using narratives [46] the understanding of unpredictable planning processes relating them to the features described for open complex systems, thus introducing complexity theory one step further into the literature of planning and regional development.

\section{VISUALIZING COMPLEXITY IN INSTITUTIONAL CHANGE}

We do not aim to contribute directly to these theories, but merely want to show that a number of concepts from complexity theory are also useful for understanding dynamics within planning practices, the interdependency of levels, and subsystems therein and the way these respond to external windows of opportunity. Seen from a complexity theory perspective, such adaptation is an internal process, which is often described as the process of self-organization that happens within the system and which can be nonlinear $[3,30]$. Self-organization is the tendency in complex systems to evolve toward order instead of disorder, which only occurs in open systems that can import energy from external sources [46]. In social systems like planning, the interaction between system and context is vital for understanding systemic adaptation.

The order exhibited by complex adaptive systems is highly dynamic, yet it can remain in a stable equilibrium state for a long time - this state is called an attractor. Most of the published literature on complexity concentrates on systems developing toward greater complexity, e.g. Waldrop [32, 60], with some emphasis on the possibility of total decline. Systems change their structure slightly to adapt to outside developments, so that they can remain within their current attractor. While being in one attractor, there are other attractors (alternative states of form and operation) present to which the system could shift, but only after a shock that drives it out of the current attractor.

What is particularly relevant to the issue of institutional change in planning is that any complex system, although seemingly unchanged, is likely to become unstable as a consequence of changes in 
its environment. Note that instability does not equally change. It only means a growing likelihood that a shift will occur in some direction at some moment. As adaptation becomes more and more difficult, the system can develop into an unstable and chaotic situation, which some complexity authors call 'the edge of chaos'. The system goes from one state of order (attractor) through a chaotic situation into another state of order or attractor (as described by Waldrop [32, 63]. The change is rapid and chaotic, and its direction is unpredictable. This change is sometimes called a catastrophe [63], although Geldof [64] calls it a crisis.

To help understand these concepts, there are two ways to visualize the development of complex systems, which are discussed below. Complex systems can be visualized as being located in a landscape of fitness $[32,64,65]$, which is illustrated in Fig. 1. The fitness landscape concept has been applied in organization science, particularly by Levinthal [66]. The fitness landscape as represented by Fig. 1 includes favorable and less favorable positions. The mountain tops represent favorable positions or attractors, while the valleys represent less favorable positions. In this fitness landscape, a complex system is preferably situated in an attractor, represented by a mountain top. It tends to move to the highest possible position in the landscape, which is most favorable. To reach this position, however, the system will have to cross valleys, which represent less favorable positions.

Pressure is needed to push a system from its current position or attractor and enable it to move through the less favorable position on to a higher mountain top. This perspective has been used by strategists to direct behavior by molding the landscape by means of incentives (for instance, reward systems). Instead of this strategic approach, we mostly use it as a descriptive, explanatory model.

A second way to visualize the development of complex systems is illustrated in Fig. 2, which represents the behavior of a complex system over time, visualizing equilibrium phases as well as sudden changes or crises as defined by Geldof [64] after Prigogine and Stengers [3]. In the beginning, a complex system is in a particular equilibrium A (1). As a result of external factors (influx of energy or information), the system develops and finally reaches a less stable zone (2). The open system tries to maintain the equilibrium state A by suppressing change. At a certain moment, the system reaches a critical point where it turns into instability (3). Here, at the edge of chaos, the system looks for and finally moves to some new equilibrium, A' or B (4); it is uncertain what the new equilibrium will be. Figure 3 schematically illustrates the evolution of a complex system over time. The system is in state $\mathrm{x} 1$.

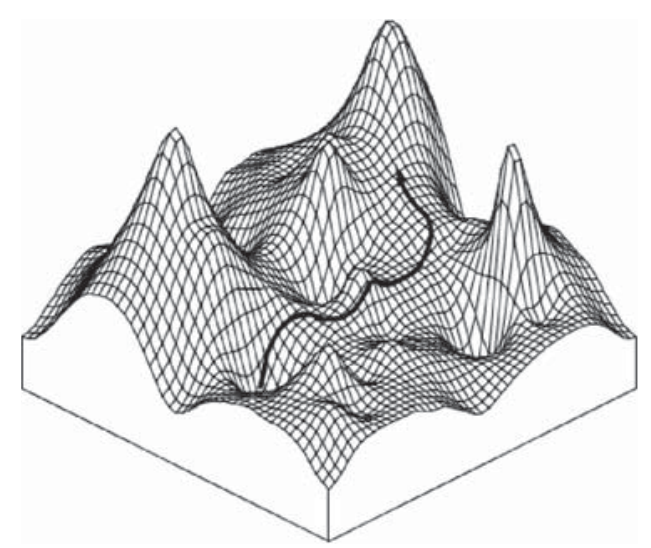

Figure 1: Fitness landscape [63, after 30] showing a complex system moving from a less favorable to a favorable position or attractor. (from: [63], after [30]). 


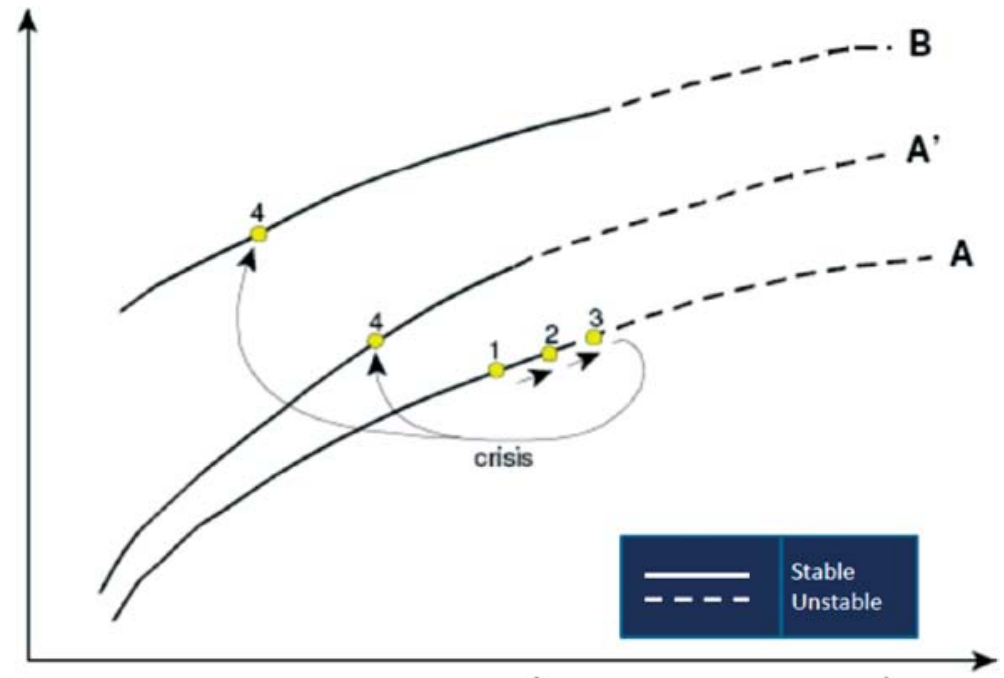

Figure 2: Schematic behavior of a complex open system with a certain characteristic (vertically) developing over time (horizontally). Tensions between the characteristics and the environment grow over time, changing the system from a stable to a more unstable state. The final result is a change in characteristics and a new stable balance with the environment (from: [64], after [3]).

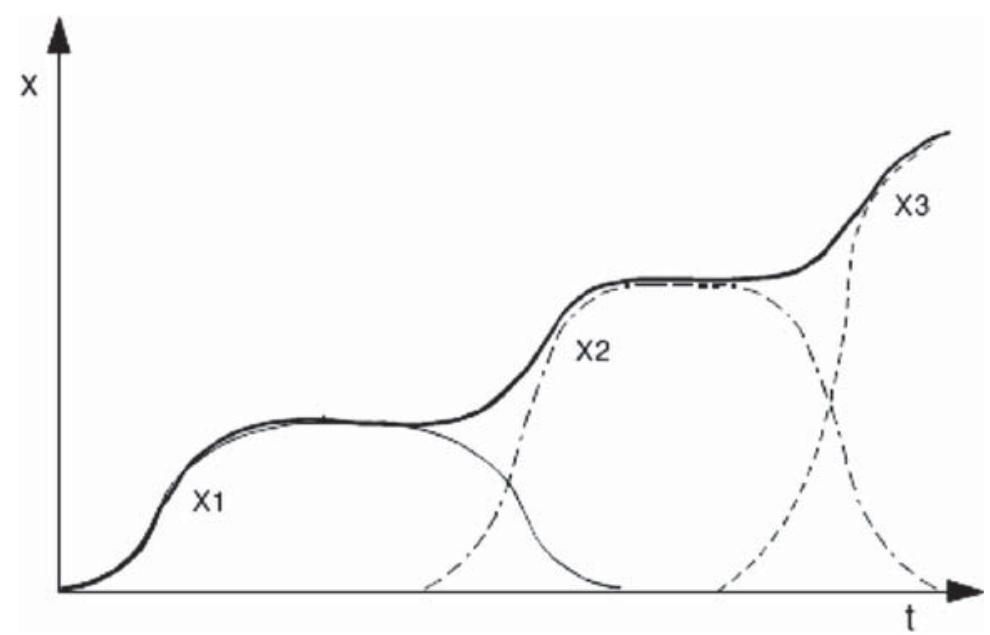

Figure 3: Evolution of a complex system showing the rising and declining complexity of the system $(x)$ in relation to time $(t)$ (from: [64], after [3]).

When this state becomes less stable or less favorable, the system quickly adapts into a new state $\mathrm{x} 2$, with a higher degree of complexity. Another possibility is a development into a lower degree of complexity, which is represented by the downward line. The shifts occur rapidly.

The pattern represented in Fig. 3 enables us to consider multiple systems with different rates of complexity developing over time. 
Our investigation of changes in land development not only demonstrated the relevance of complexity theory and the limitations of instrumentalism, but also aimed to find out to what extent the stories obtained from our fieldwork can actually be interpreted in terms of the present theoretical framework (Section 8).

\section{METHODOLOGY}

In search of the real cross-national lessons on institutional change in land development systems, we looked for an alternative to the instrumental paradigm of mutual learning and the evolutionary assumption. The FARLAND project on innovation in land development provided us with an opportunity to systematically investigate the stories behind systemic innovations. What trains of events had produced these innovations? What drove these trajectories and what directed them? Can such processes be managed at all? Can trajectories of change be deliberately induced in alternative planning practices as well?

We first asked all partners in the FARLAND project to identify and describe their most striking innovative land development practices, using a fact- and data-based questionnaire asking about the new approach, the old and now replaced approach and the area where the implementation took place or was taking place. This implies that we only studied those cases of institutional changes in land development practice that eventually effectively led to systemic change.

On the basis of the answers to the questionnaire, we selected 14 of the projects for a more detailed description [1] based on in-depth open interviews with the key regional and local persons involved, using a Grounded Theory approach. We were able to actually visit all of these 14 projects, and each project was discussed with the local people involved and the researchers and practitioners of the FARLAND project (www.farland.eu). Four of the projects descriptions were then re-described in terms of complexity theory, following Geldof [64].

The qualitative in-depth research was based on the Grounded Theory principles developed by Glaser and Strauss [67] to generate new theory grounded in data or field evidence. We followed Strauss and Gorbin [68], who favor a descriptive approach using rich data from directive and interpretative questions to key persons, and Charmaz [69], who reviewed grounded theory as delivering perspective knowledge about practical experiences. The essence of our approach was not primarily the production of testable scientific truth; rather, it aimed to produce joint understanding [70].

We used the qualitative data from the in-depth interviews to formulate a narrative of the innovation process in the four selected projects. We then re-described the innovation processes in terms of dynamic complex systems following $[1,42,64,71]$ and tried to re-interpret Fig. 3 in this paper, showing the development of the complexity of a complex system over time.

In researching innovative approaches and examining them as complex systems, we looked for sudden changes or crises occurring. We distinguished between the new and the old routine and identified five components in the processes of sudden change. In discussing the innovative processes which were regarded as complex systems with the key persons, we identified:

1. the current routine of the complex system (current attractor),

2. changes in the environment of a complex system resulting in pressure to change its routine,

3. micro-scale attempts within the complex system to adapt to the changes within the current routine,

4. chaotic phases in the complex system where pressure became so large that current routines were no longer appropriate,

5. triggers from outside the complex system, i.e. sudden occurrences resulting in changes,

6. sudden and rapid changes to the routines of the complex system,

7. the new routine of the complex system. 
We studied Fig. 3 in this paper to see if we could redraw it using the information about the innovation process that we had collected in the field, to try and identify complex systems showing growing complexity over time, and to understand this development. This enabled us to systematically describe and discuss the process of change in all cases investigated.

The added value for planners would be that our work shows how institutional change emerges from a chain of changes, from micro- to macro-level, via a nested sequence of attractor shifts, in response to changes in the world directly surrounding the primary system.

A journal article obviously cannot accommodate the wealth of information we obtained in our study. Reducing the 14 cases to a brief table format would still fail to convincingly make our point. In the next paragraph, we therefore describe the results for one case; the Vila Verde case in Galicia (Spain), as an exemplar of what we found.

\section{INNOVATIVE APPROACHES IN LAND DEVELOPMENT, THE VILA VERDE CASE}

\subsection{Galicia, formal story of Vila Verde}

This section discusses one of the four FARLAND projects that we re-described in terms of complexity concepts [1]: the Vila Verde project in Galicia, Spain. All innovation processes in land development that we considered show at least a balance between institutional design at a higher level of scale and a multitude of smaller efforts of institutional design at a lower level of scale. We decided to describe Vila Verde because it shows how actions at a lower scale level have been decisive for design at the higher level. The formal story is as follows.

The Galician population is highly dispersed, resulting in 1.1 population entities per $\mathrm{km}^{2}$ and over 26,000 villages. Although the total population is stable, most of the territory is suffering from population decline [72]. Economic activity in the rural areas is based on agriculture and forestry. Land occupation is $32 \%$ forestry and $33 \%$ shrub lands; agriculture only covers $25 \%$ of the land, which is very low compared to the whole of Spain (50\%) and the EU-25 (41\%) [73]. Most of the scrublands have resulted from land abandonment processes. A major cause of these processes is the structural condition of Galician agriculture. There is a dual structure of land tenure. On the one hand, there is a type of private common land owned by around 2,300 villages, with an average size of more than 200 hectares. These lands cover about $22 \%$ of the Galician land surface. The lands are mainly located in the mountainous areas and are often unmanaged or in use for very low intensity forestry. On the other hand, there is individual private property land. These lands are highly fragmented, as a consequence of the highly dispersed population, traditional agricultural economics, and a tradition of property inheritance by subdividing the land within families. Land mobility is very limited; people tend to keep ownership of their lands even if they abandon them. As a consequence, the average farm size is small: about 10 hectares, with 25 parcels per farm, highly fragmented and uneconomically shaped. The situation is even worse in the mountainous areas, where Vila Verde is situated. The number of farms has fallen by about 255 during the last decade [73], with even higher rates in the mountainous areas, where migration levels are high due to low availability of services, facilities, and farm-related jobs. Thousands of small villages are becoming deserted.

Young people in rural Galicia, with its highly fragmented ownership of agricultural land, are leaving the villages and moving to the cities where they can find jobs. They leave their parcels abandoned, which causes more fragmentation. The new regional government has established a program of rural development to keep the rural areas livable. The program includes funding to strengthen the common grounds tradition to reinvigorate local farming. Vila Verde is the first example of this new mode of rural development. The nine remaining families, some of them non-farming, now own a share in 
one common farm, which is big and efficient enough to be economically viable, and the families can stay and make a living for themselves in the village.

\subsection{Re-description of the case: the perspective of the regional government ${ }^{1}$}

From the point of view of the regional government, rural decline had not been a matter of interest for decades. Regional policy was dominated by the social democrat party and focused on further development of the larger towns and cities as the economic centers of Galicia (1). There was population growth in the cities, at the cost of rural decline (2), which was more or less accepted, though some minor programs were established, like the stimulation program on grassland farming (3). As a consequence, thousands of small villages were abandoned, as were thousands of hectares of agricultural land; the people who had moved to the city saw their roots disappear (4). At the beginning of the new millennium, there were some major ecological incidents: the wreck of an oil tanker caused a large oil spill on the Coruna coast, and some years later huge forest fires destroyed large parts of the Galician rural forests (5). This resulted in rural decline becoming an important issue among the inhabitants of Galician towns and cities, many of them having strong rural roots. As a result, the next regional elections brought a radical shift in the political landscape. A more nationalist government was instated (6), which gave high priority to rural decline and set up major programs. There was now a need for successful practices and Vila Verde was one of the very few examples available, and became the model project for the new policy and its approach (7).

\subsection{Vila Verde, formal story}

The above story has been analyzed in more detail in our grounded research, as part of the FARLAND project. This involved discussions between the inhabitants, regional experts, and international experts. An in-depth interview was held with the Galician governor on Rural Affairs, with Eloy, the regional program manager and with Antonio, the Vila Verde inhabitant who took the original initiative.

Vila Verde appears to be representative of thousands of small villages in Galicia. Only nine families are left in this village, six of whom are engaged in farming, mainly cattle grazing. Over time, many people have left the village for one of the cities, leaving their land abandoned. There is no local tradition of selling or renting the land: people simply keep the land because it is traditionally family owned and it is regarded as a kind of insurance. Because of this trend, land use by the remaining farms and families is highly fragmented, with many parcels completely abandoned. Meanwhile, the local population is growing older. Common grounds are poorly managed and not actively used. There is no investment in local farming practices, and production and benefits are diminishing.

This system of production is about to break down, as it has not been able to adapt to changing circumstances. The fitness landscape has changed, but the village is stuck in an old attractor that is losing its power. The pressure to make the shift to another attractor is building up, and this is characteristic of many Galician villages.

The initiative for the shift came from Antonio. He lived in Vila Verde and worked in a factory outside the village, where he met many different people and picked up new ideas about rural farming. He worried about the factory and his job, and when he heard that two more families in his village intended to stop farming, he realized that this might be the end of his village. In his talks with visitors to the factory, he heard about a small village project in the Spanish province of

\footnotetext{
1 Numbers [1-7] correspond with the numbers mentioned in section 6 .
} 
Asturias, where some remaining families survived as farmers by utilizing their common grounds very effectively. He had also become acquainted with Eloy, the regional manager of an environmental program trying to preserve grassland farming in Galicia. Together, they organized an excursion to the Asturias project, which was attended by a member of each of the remaining Vila Verde families.

This was the start of an intensive negotiation process in the village, discussing various options for the future. The result was that the nine families decided to establish one common farm, operating on existing farmlands and all common grounds, which would be a modern land-based farm. Each of the families, both farming and non-farming, participated.

At the time, this solution was unique to Galicia and its thousands of small villages. A few years later, however, regional elections were held, resulting in a new regional government with a more nationalist orientation. At the same time, Galicia was afflicted by several environmental hazards, including an oil pollution disaster on the Galician coast and huge forest fires, which created a strong awareness of the threat to Galician rural life, where the larger part of the urban population still had its roots. In response to these events, a policy was designed to stop the abandonment of rural villages, with Eloy as its program manager.

For him and for the new policy, Vila Verde was one of the very few successful examples of a Galician village being revitalized, and their micro-level innovation was therefore hailed as one of the icons of the new policy for rural Galicia. Interestingly, it shows how a small experiment can be highly influential in establishing new policies. The story also shows the importance of individual people like Antonio and Eloy, who personally initiated and established the innovation.

Consideration of this story allows us to answer our first question. Antonio and Eloy had a decisive influence on the definition of the new regional policy. They succeeded in developing a new farming system for a small village, which meant Vila Verde was the only surviving village out of thousands of comparable villages that have all been abandoned. Without Antonio and Eloy, the new Vila Verde farming system would not exist, and there would not have been a local pilot project which could serve as a starting point for the new regional policy.

\subsection{Re-description of the case: the perspective of the village}

Let us reconstruct the various phases in this process at the level of the village. At Vila Verde, the current routine (1) (numbers refer to the stages described in Section 6) was that people owned and exploited small traditional farms based on cattle grazing. Land ownership was highly fragmented, so that agricultural practice was very inefficient. The change in the environment (2) which caused pressure on this routine was that young people were leaving their village and moving to the towns to find jobs and opportunities, leaving their parcels of land abandoned. Farming at Vila Verde became more and more difficult, due to ongoing fragmentation of land ownership and a growing area of abandoned land. As a result, the standard of living declined. The people of Vila Verde had previously tried to adapt (3) to the new situation by making plans for a large industrialized farm in the early 1990s, but this attempt was unsuccessful, because of a lack of funding. The problem became acute (4) when another two of the six remaining families announced their intention to stop farming. The system was unstable, far from equilibrium. One of the inhabitants, Antonio, then proposed a new idea (5) which offered the village a new and previously unknown opportunity to survive. Together with Eloy, he came up with the idea of a common farm in which each family would own a share. After many meetings and a field trip, the idea was accepted and implemented (6) and brought the village into a new stable situation for the time being (7), offering a way to live and earn money in the village. Vila Verde thereby became one of the few villages that finally were not abandoned. 


\subsection{Re-description of the case: the perspective of Antonio, inhabitant of Vila Verde}

From the specific point of view of Antonio, we can make a similar reconstruction. He had lived his whole life in Vila Verde, a small village with families making their living mainly from small-scale farming (1). However this traditional life was under threat: young people were leaving the village and the whole of the rural area, threatening rural life. Consequently, his job at an agriculture-related factory outside Vila Verde was also under threat (2). At an earlier stage, he had contacted regional Galician authorities with an idea to develop more intensive farming practices in the village (3), but program manager Eloy did not consider this a viable investment for the regional policy makers, because its economic basis was not strong enough. When another two of the six farming families announced their plan to stop farming, the situation became acute; something had to be done (4). Antonio knew a lot of people outside the village, with whom he talked about his concerns. One of them gave him the idea of a common farm, in which each of the village families would own a share. There was an example of such a scheme in Asturias. Antonio remembered Eloy, realized that this idea could interest Eloy, and contacted him. Together with a representative of each family, they visited the Asturias village and concluded that their approach had great potential (5). After many meetings and negotiations, the Vila Verde people decided to establish a common farm (6), which currently enables them to make a living in Vila Verde (7).

\subsection{Re-description of the case: the perspective of Eloy, regional program manager}

Eloy is a policy maker in Galicia, who had been working for more than a decade on rural development to keep the rural areas stable (1). He was trying to stop the ongoing abandonment of land and villages (2) and was the manager of a program to stimulate grassland farming, based on local traditions on the one hand and adapting to new opportunities on the other (3). Meanwhile, thousands of small villages were being abandoned (4); it looked like an unstoppable development. Then finally there was an opportunity to come up with an alternative, when Antonio contacted him with his idea, based on the Asturias example. After a field trip and a lot of village meetings and negotiations, a new form of common farming was developed, with shares for each village family, offering a common economic basis for the whole village, with farming practice in balance with local traditions and conditions (5). The plans were elaborated and implemented (6), and the village escaped the fate of thousands of others which were abandoned, even becoming a pilot project in the newly established regional policy (7).

\section{CONCLUSIONS}

We asked ourselves two questions in this paper. The first question is whether changes in planning practices can represent the aggregated effect of many smaller efforts of institutional design at a low level of scale. We can conclude that this was indeed the case in the example of Vila Verde. We were able to re-describe this case using the seven components that we defined in Section 6, to understand the process of innovation in Galicia. The various phases in the shift in Galician land use from one routine to another thus coincide very well with concepts used in modeling the behavior of complex systems.

The innovative approach at Vila Verde is illustrative of the many cases of institutional change we analyzed for this study. These cases can be understood as complex processes exhibiting the basic rules of Complex Adaptive Systems. From this perspective, we can conclude that the systemic innovation in Galician land development was clearly a product of micro-innovation that was amplified by a favorable context; recognition of its relevance to other villages and a receptive environment at the regional governmental level. This institutional change was in fact a cascade of changes. 
Vila Verde is only a small village in Galicia where some people accidentally met and developed a new idea, which might present a solution to the rural problems. It was not planned, was highly accidental, and developed in a very peripheral area. This is interesting for our understanding of institutional change. It is especially in complex situations that small, unexpected, and uncertain developments in the periphery can suddenly push a complex system from one state of equilibrium to a completely different one. Local people in Vila Verde and the local Vila Verde pilot project had a decisive influence on the regional policy of the new Galician government to counteract rural decline.

Small and sometimes even unexpected efforts of institutional design at a low level of scale can under certain circumstances become aggregated to evolve into collective institutions at a higher level. These observations show that institutional change can be about evolution from below. In Anderson's words (Anderson [52] p. 228): 'In environments far from equilibrium, where cascades of change are constantly playing out and overlapping with one another, adaptation must be evolved, not planned. Adaptation is the passage of an organization through an endless series of organizational microstates that emerge from local interactions among agents trying to improve their local payoffs. The task of those responsible for the strategic direction of an organization is not to foresee the future or to implement enterprise-wide adaptation programs, because nonlinear systems react to direction in ways that are difficult to predict or control. Rather, such managers establish and modify the direction and the boundaries within which effective, improvised, self-organized solutions can evolve.'

Looking back on our analyses of these and many other examples, we argue that current CAS theories are helpful for planners and policy scientists to adopt a non-instrumentalist perspective on processes as well as on the role of planners and decision-makers. It calls for modest ambitions for institutional design. However, some limitations of the simplicity of the model became evident when confronted with our observations of reality. The concept of the fitness landscape provides insights into the situation of a particular complex system at one particular moment, as illustrated in Fig. 3. However, it does not explain the situation of two or more different and potentially interacting complex systems at the same time, which consider different situations as favorable. The fitness landscape presented in Fig. 3 is a static model: it gives information on the situation at a particular moment and not on the potential development of the complex system over time, which is necessary when we discuss innovation processes.

Nor does it offer information about the development over time of the fitness landscape itself, which is constantly changing due to developments outside the landscape considered. Therefore, we need to include the embeddedness of processes in wider processes, and the relevance of the interaction for the development of both. Although in Galicia, the new farming model satisfied an obvious general need, this peak in the fitness landscape could not have been foreseen. The fitness landscape helps to explain, but not to predict.

We conclude from our study across 14 stories about institutional shifts in land development that far-from-equilibrium states can occur at a range of levels (local or systemic; organizational or in the object addressed by the system; in its environment or in its own systemic operation), and that systemic institutional change can emerge from a chain reaction initiated locally. We would like to emphasize the importance of nested dependency of landscapes and, as a consequence, the prerequisite of timely conflation of peaks, to a greater extent than is done in the existing literature. As we showed in the Vila Verde example, three strands of seemingly unrelated entities, the village of Vila Verde, its inhabitant Antonio, and the regional program manager Eloy, interacted and created a common new peak; a new farming system that was strong enough to face the regional challenge of rural land abandonment. Still, Vila Verde would have been just one at least temporarily successful village, if its development had not become embedded in the new Galician policy, as is visualized in Figs. 4, 5 , and 6 . 


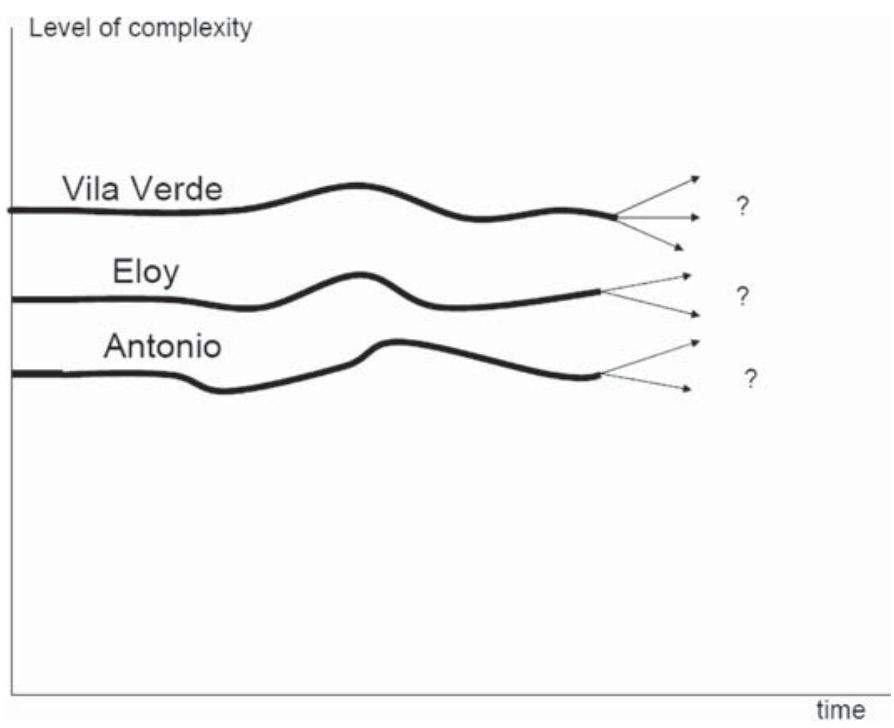

Figure 4: Three complex systems initially develop independently. As a result of external influences, they reach a chaotic phase.

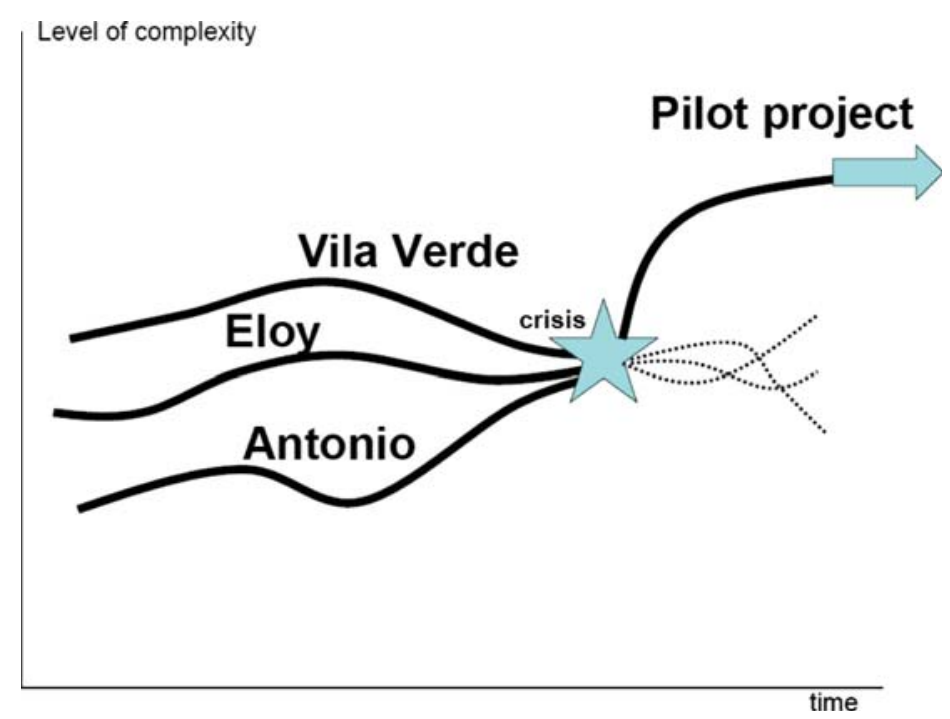

Figure 5: When they interact, the result is a joint pilot project, at a higher level of complexity. The dotted lines show what could have happened if the three systems had not interacted. The horizontal axis represents time; the vertical axis represents level of complexity.

The coincidental nature of this conflation is evident, as thousands of other Galician villages did not manage to adapt in time and were abandoned. This reflects the basic notion in complexity Theory, that crises, in the constructive sense of the word, as the embedment of the Vila Verde development in the new Galician policy occur unexpectedly and start in the peripheral parts of a system 


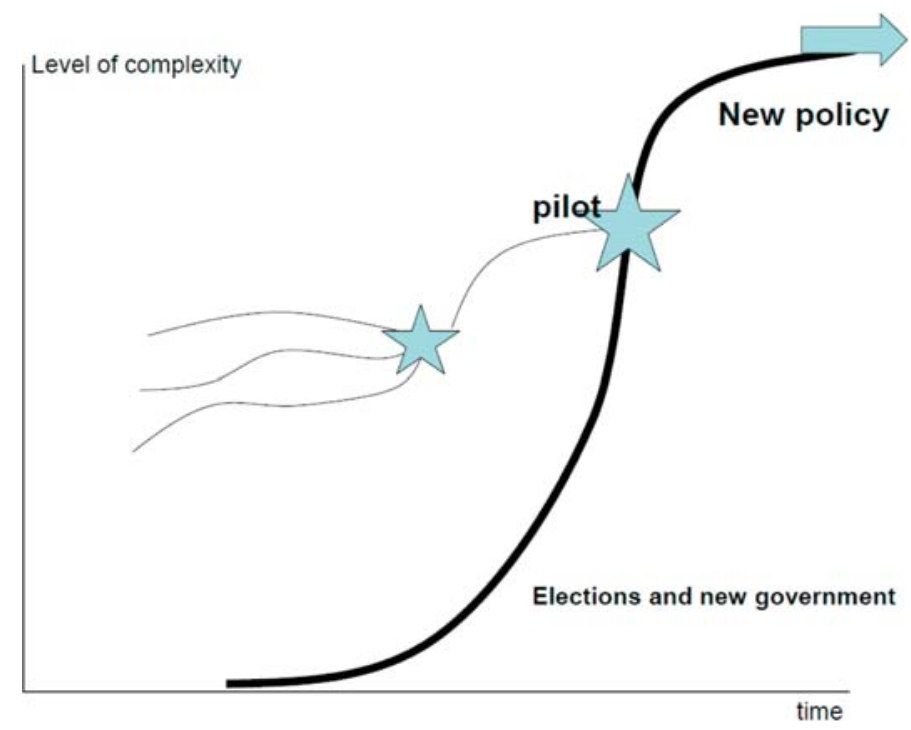

Figure 6: The outcome of the elections was a new government. The pilot project became an important example for the future policy and had great influence on the ideas incorporated in the new policy. The horizontal axis represents time; the vertical axis represents level of complexity.

(e.g. Timmermans) $[28,32,64,71,74]$. Small peripheral events can cause an existing system to change radically, reaching a new mode with another level of complexity.

What is interesting to planning research, which tends to concentrate very much on the formal governmental processes, is that spontaneous bottom-up initiatives may be peripheral in large organizations and institutions, but nonetheless have the potential to generate more general change through the interactions between agents. Acceptance of this complexity theory, which in many related fields of science has become so important, can help planning research to better understand the sometimes unexpected processes of change.

We have to acknowledge that planning processes are sensitive to small differences in conditions. This does not detract from the relevance of planning or public policy making; it merely opens up new opportunities for politicians, planners, and managers. As Anderson ([46] p.220) puts it, 'Complex Adaptive System models afford exciting new opportunities for analysing complex systems without abstracting away their interdependencies', shedding light on the internal ecology within organizations. Where we define innovation as possibly uncertain and unexpected, the question can be raised how politicians, planners, or top managers rate their ability to influence innovation. How do they identify and frame a crisis or a possible solution? Can they create constructive sparks in systems that are obviously far from equilibrium? What competences are necessary to properly anticipate a crisis? The instrumental paradigm produces managers who often get in the way of activities that offer their own self-regulation, form, and self-correcting tendencies. The question is whether fitness landscapes can be deliberately molded, and whether crises can be induced, supported, or suppressed, enabling indirect partial control over change while respecting grass-root knowledge as well as the inevitability of certain trends that are beyond our control.

This understanding raises new issues. One thing we need to investigate is the detailed morphology of 'crises'. In our example, the crisis was caused by bottom-up peripheral initiatives coinciding in an 
unplanned way with a general trend at a higher level of scale. We agree with Batty [75], who argues that there is a need for a classification of the phenomena that we described as crises. We think that a better understanding can be gained from historical studies and from narrative-based research [76] in real 'on the ground' processes of crisis and change. Further research is required to know if it is possible to identify and understand the patterns and morphology of crises. The role of human resources also becomes important in this respect, as was stressed by authors like Montalvo [77] and Chapman [78].

\section{REFERENCES}

[1] Timmermans, W. et al., Innovation: expecting the unexpected. Farland, near Future, eds P. Van der Jagt, et al, 4C Hungary, pp. 32-45, 2007.

[2] Van Dijk, T., Transplanting instruments that work: four practical lessons on eliminating erronous assumptions. Planning Theory and Practice, 7(4), pp. 421-442, 2006b. doi:http://dx.doi. org/10.1080/14649350600984758

[3] Prigogine, I. \& Stengers, I., Order out of Chaos. Bantam Books: New York, 1984.

[4] Buitelaar, E., Lagendijk, A. \& Jacobs, W., A theory of institutional change: illustrated by Dutch city provinces and Dutch land policy. Environment and Planning A, 39, pp. 891-908, 2007. doi:http://dx.doi.org/10.1068/a38191

[5] Hayek, F.A., The Constitution of Liberty. Routledge: London, 1960.

[6] Kingdon, J.W., Agendas, alternatives and public policies. Harper Collins College Publishers: New York, 1984.

[7] Barras, R., Interactive innovation in financial and business services. Research Policy, 19, pp. 215-237, 1990. doi:http://dx.doi.org/10.1016/0048-7333(90)90037-7

[8] Miozzo, M. \& Soete, L., Internationalisation of services: a technological perspective. Technological Forecasting and Social Change, 67, pp. 159-185, 2001. doi:http://dx.doi.org/10.1016/ $\underline{\text { S0040-1625(00)00091-3 }}$

[9] Drejer, I., Identifying innovation in surveys of services: a Schumpeterian perspective. Research Policy, 33(3), pp. 551-562, 2004. doi:http://dx.doi.org/10.1016/j.respol.2003.07.004

[10] Miles, I., Services innovation: coming of age in the knowledge-based society. International Journal of Innovation Management, 4(4), pp. 371-389, 2000. doi:http://dx.doi.org/10.1016/ S1363-9196(00)00020-2

[11] Saviotti, P.P. \& Metcalfe, J.S., A theoretical approach to the construction of technological output indicators. Research Policy, 13(3), pp. 141-151, 1984. doi:http://dx.doi.org/10.1016/ $\underline{0048-7333(84) 90022-2}$

[12] Coombs, R. \& Miles, I., Innovation measurement and services: the new problematique. Innovation Services in the Services Economy: Measurement and Case Study Analysis, eds. J.S. Metcalfe \& I. Miles, Kluwer Academic Publishers: Boston, pp. 85-103, 2000.

[13] Geels, F.W., Processes and patterns in transitions and system innovations: refining the co-evolutionary multi-level perspective. Technological Forecasting and Social Change, 72(6), pp. 681-696, 2005. doi:http://dx.doi.org/10.1016/j.techfore.2004.08.014

[14] Tukker, A. \& Butter, M., Governance of sustainable transitions: about the 4(0) ways to change the world. Journal of Cleaner Production, 15, pp. 94-103, 2007. doi:http://dx.doi. org/10.1016/j.jclepro.2005.08.016

[15] Kash, D.E. \& Rycroft, R., Emerging patterns of complex technological innovation. Technological Forecasting and Social Change, 69, pp. 581-606, 2002. doi:http://dx.doi.org/10.1016/ $\underline{\text { S0040-1625(01)00171-8 }}$

[16] Macintosh, R. \& MacLean, D., Conditioned emergence: a dissipative structures approach to transformation. Strategic Management Journal, 20(4), pp. 297-316, 1999. doi:http://dx.doi. org/10.1002/(SICI) 1097-0266(199904)20:4<297::AID-SMJ25>3.0.CO;2-Q 
[17] Cheng, Y.T. \& Van Der Ven, A.H., Learning the innovation journey: order out of chaos. Organization Science, 7(6), pp. 593-614, 1996. doi:http://dx.doi.org/10.1287/orsc.7.6.593

[18] Ayres, R.U., Toward a non linear dynamics of technological progress. Journal of Economic Behavior and Organization, 24, pp. 35-69, 1994. doi:http://dx.doi.org/10.1016/ 0167-2681(94)90053-1

[19] Van Holst, F. \& Thomas, J., Once upon a time an a Far, FARLAND. Editorial. Farland, near Future, eds P. Van der Jagt, et al. 4C Hungary, pp. 9-11, 2007.

[20] Lopez, Q.O. et al., What's cooking in land development? Farland, near Future, eds P. Van der Jagt, et al, 4C Hungary, pp. 16-31, 2007.

[21] Magel, H., Urban Rural Relationship for Sustainable Development. 2nd FIG Regional Conference. Geomatik. Schweiz, 2004.

[22] Steudler, D., Rajabifard, A. \& Williamson, I.P., Evaluation of land administration systems. Land Use Policy, pp. 371-380, 2004. doi:http://dx.doi.org/10.1016/j.landusepol.2003.05.001

[23] Bromley, D.W., Land and economic development: new institutional arrangements for the 21st century. Toward a 2015 vision of land, a celebration of ICLPST's 100 Regular sessions, 2006.

[24] Derlich, F., Land Consolidation: A key for Sustainable Development - French Experience. XXII FIG international congress, 2002.

[25] Eskildson, K.A, Danish land consolidation. The International Symposium FAO, GTZ, FIG, ARGE Landentwicklung and TUM on Land Fragmentation and Land Consolidation in CEEC: A gate towards Sustainable Rural Development in the New Millennium, 2002.

[26] Uimonen, M., Actual developments of land consolidation in Finland. FIG Commission 7: Symposium on Modern Land Consolidation, 2004.

[27] Van Dijk, T. \& Kopeva, D., Land banking and Central Europe: future relevance, current initiatives, Western European past experience. Land Use policy, 23(3), pp. 286-301, 2006. doi:http://dx.doi.org/10.1016/j.landusepol.2004.07.005

[28] Prigogine, I. \& Stengers, I., Order out of Chaos. Bantam Books: New York, 1984.

[29] Prigogine, I., Science, civilisation and democracy: values, systems, structures and affinities. Futures, august 1986, pp. 493-507, 1986.

[30] Kauffman, S., The origins of order. Oxford University Press: New York, 1993.

[31] Gleick, J., Chaos: Making a New Science. Viking: Penguin, 1987.

[32] Waldrop, M.M., Complexity, the Emerging Science at the Edge of Order and Chaos. Penguin books: London, 1992.

[33] Lewin, R., Complexity, Life at the Edge of Chaos. Macmilan: New York, 1992.

[34] Byrne, D., Complexity, configurations and cases. Theory Culture Society, 22, pp. 95-111, 2005. doi:http://dx.doi.org/10.1177/0263276405057194

[35] Cilliers, P., Complexity, Deconstruction and Relativism. Theory Culture Society, 22, pp. 255-267, 2005. doi:http://dx.doi.org/10.1177/0263276405058052

[36] Axtell, R. \& Epstein, J. Growing Artificial Societies: Social Science from the Bottom Up. Brookings Institution: Washington DC, 1996.

[37] Barabasi, A., Linked. Perseus: Cambridge, 2002.

[38] Scheffer, M. et al., Early-warning signals for critical transitions. Nature, 461/3, pp. 53-59.

[39] Artigani, R., Leadership and uncertainty: complexity and the lessons of history. Futures, 37, pp. 595-603, 2005.

[40] Mason, R.B., The externa environment's effect on management and strategy, a complexity theory approach. Management Decision, 45(1), pp. 10-28, 2007. doi:http://dx.doi. org/10.1108/00251740710718935

[41] Green, N., Art and complexity in London's East End. Complexity 4(6), pp. 14-21, 1999. doi:http://dx.doi.org/10.1002/(SICI)1099-0526(199907/08)4:6<14::AID-CPLX3>3.0.CO;2-S 
[42] Timmermans, W., Crises and Innovation in Sustainable Urban Planning. WIT Press. Advances in Architecture (18), pp. 53-63, 2004.

[43] Prigogine, I., Le fin des certitudes (The end of certainty). Editions Odile Jacob: Paris. France, 1996.

[44] Pulselli, R.M. \& Tiezzi, E., City out of chaos. WIT Press, 2009.

[45] Pulselli, R.M. \& Romano, P., Urban Systems Dynamics. Alinea editrice: Firenze, 2009.

[46] Tiezzi, E., The Essence of Time. WIT Press: Southampton, Boston, 2003.

[47] Geraldi, J.G., The balance between order and chaos in Multi-project firms: a conceptual model. International Journal of Project management 26, pp. 348-356, 2008. doi:http://dx.doi. org/10.1016/j.ijproman.2007.08.013

[48] Hodgson, D., Project work: the legacy of bureaucratic control in the post-bureaucratic organization. Organization, 11, pp. 81-100, 2004. doi:http://dx.doi.org/10.1177/1350508404039659

[49] Kelly, J. \& Stark, D., Crisis, recovery, innovation: responsive organization after September 11. Environment and Planning A, 34, pp. 1523-1533, 2002. doi:http://dx.doi.org/10.1068/a35176

[50] Schneider, M. \& Somers, M., Organizations as complex adaptive systems: implications of Complexity Theory for leadership research. The Leadership Quarterly, 17, pp. 351-365, 2006. doi:http://dx.doi.org/10.1016/j.leaqua.2006.04.006

[51] Vicenzi, R. \& Adkins, G., A tool for assessing organizational vitality in an era of complexity. Technical Forecasting and Societal Change, 64, pp. 101-113, 2000. doi:http://dx.doi. org/10.1016/S0040-1625(99)00074-8

[52] Anderson, P., Complexity Theory and Organisation Science. Organisation Science, 10(3), pp. 216-232, 1999. doi:http://dx.doi.org/10.1287/orsc.10.3.216

[53] Gell-Mann, M., Complex adaptive systems. Complexity: Metaphors, Models and Reality, eds. G.A. Cowan, D. Pines \& D. Meltzer, Addison-Wesley: Reading, pp. 17-29,1994.

[54] Pirsig, R.M., Lila, an inquiry to morals. Bantam, 1991.

[55] Shulla, K. \& Timmermans, W., Unstable city. Surviving the Suburb, ed. G. Harbusch, et al., Episode Publishers: Rotterdam, 2008.

[56] Jonge, J. de, Landscape Architecture between Politics and Science, an Integrative Perspective on Landscape Planning and Design in the Network Society. PhD thesis Wageningen UR, 2009.

[57] Roggema, R.E. \& Van Den Dobbelsteen, A.A.J.F., Swarm planning: development of a new planning paradigm, which improves the capacity of regional spatial systems to adapt to climate change. Proceedings World Sustainable Building Conference (SB08), September 2008, Melbourne, 2008.

[58] Crawford, T.W., Messina, J.P., Manson, S.M. \& O'Sullivan, D., Guest editorial. Environment and Planning B. Planning and Design, 32, pp. 792-798, 2005. doi:http://dx.doi.org/10.1068/ b3206ed

[59] O'Sullivan, D., Complexity science and human geography. Trans Inst Br Geogr NS, 29, pp. 282-295, 2004. doi:http://dx.doi.org/10.1111/j.0020-2754.2004.00321.x

[60] O'Sullivan, D., Manson, S.M., Messina, J.P. \& Crawford, T.W., Guest editorial. Environment and Planning A, 38, pp. 611-617, 2006.

[61] Portugali, J., Complexity theory as a link between space and place. Environment and Planning A, 38, pp. 647-664, 2006. doi:http://dx.doi.org/10.1068/a37260

[62] Manson, S., O'Sullivan, D., Complexity theory in the study of space and place. Environment and Planning A, 38, pp. 677-692, 2006. doi:http://dx.doi.org/10.1068/a37100

[63] Cohen, J. \& Stewart. I., The Collapse of Chaos, Discovering Simplicity in a Complex World. Viking, 1994.

[64] Geldof, G.D., Omgaan met complexiteit bij integraal waterbeheer. TAUW: Deventer, 2001. 
[65] Langton, C.G., Taylor, C., Farmer, J.D. \& Rasmussen, S., Artificial life II. Santa Fe Institute Studies in the Sciences of Complexity. Proceedings vol. 10. Redwood City, 1992.

[66] Levinthal, D.A. \& Warglien, M., Landscape Design: designing for local action in complex worlds. Organisation Science, 10(3), pp. 342-357, 1999. doi:http://dx.doi.org/10.1287/ orsc. 10.3 .342

[67] Glaser, B. \& Strauss, A., The discovery of Grounded Theory: Strategies for qualitative research. Aldine: Chicago, 1967.

[68] Strauss, A.L. \& Gorbin, J., Basics of Qualitative Research: Techniques and Procedures for Developing Grounded Theory, 2nd ed. Thousand Oaks. CA Sage, 1998.

[69] Charmaz, K., Constructing Grounded Theory: A Practical Guide through Qualitative Analysis,Sage publishers: London, 2006.

[70] O'Connor, M.K., Ntting, F.E. \& Thomas, M.L., Grounded Theory: Managing the challenge for those facing Institutional Review Board oversight. Qualitative Inquiry, 14(1), pp. 28-45, 2008. doi:http://dx.doi.org/10.1177/1077800407308907

[71] Timmermans, W., The complex planning of innovation. WIT Transactions on Ecology and the Environment, 122, pp. 581-590, 2009. doi:http://dx.doi.org/10.2495/ECO090531

[72] INE (National Statistics Institute) Cifras oficiales de población: padrónmunicipal, available at http://www.ine.es/jaxi/menu.do?type=pcaxis\&path=/t20/e245/\&file=inebase, 1993, 2001, 2002

[73] Eurostat, Farm Structure Survey 2003, 2007. available at http://epp.eurostat.ec.europa.eu/portal/page/portal/agriculture/data/database.

[74] Timmermans, W., Beyond predictability. Management of natural resources, sustainable develoment and ecological hazards. WIT Transactions on Ecology and the Environment, 1, pp. 13-19, 2006.

[75] Batty, M., Editorial. Environment and Planning B. Planning and design, 35, pp. 379-380.

[76] Uprichard, E. \& Byrne, D., Representing complex places: a narrative approach. Environment and Planning A, 38, pp. 665-676, 2006. doi:http://dx.doi.org/10.1068/a37333

[77] Montalvo, C., What triggers change and innovation? Technovation, 26, pp. 312-323, 2006. doi:http://dx.doi.org/10.1016/j.technovation.2004.09.003

[78] Chapman, R. \& Hyland, P., Complexity and learning behaviors in product innovation. Technovation, 24, pp. 553-561, 2004. doi:http://dx.doi.org/10.1016/S0166-4972(02)00121-9 